\title{
Childhood factors associated with complete and clinical asthma remission at 25 and 49 years
}

\author{
To the Editor:
}

Asthma can go into remission later in life in approximately $35 \%$ of all patients [1]. Asthma remission is associated with childhood onset of asthma [2,3], the male sex, smoking cessation, initially less severe airway obstruction and, notably, more severe bronchial hyperresponsiveness (BHR) $[4,5]$. Unfortunately, patients in asthma remission may show relapse later in life. Data regarding childhood factors that predict clinical asthma remission in adulthood are sparse, and even fewer data on complete asthma remission [6] or the persistence of asthma remission throughout the lifespan are presently available. Therefore, the aim of the current study is to explore whether asthma remission persists in children, followed from childhood up to an average age of 49 years. Furthermore, we determined which factors in childhood are associated with clinical and/or complete asthma remission that persists during adulthood.

An asthma cohort was created from 1972-1976 (visit 1) and re-investigated from 1987-1989 (visit 2) [7] and 2013-2014 (visit 3). At visit 1, 406 children diagnosed with asthma were referred to the University Medical Center Groningen, and characterised by extensive standardised questionnaires, peripheral blood measurements, BHR, lung function and skin prick tests. At visit 2, 285 children (209 children with BHR at visit 1) were re-examined in young adulthood. At visit 3, 102 subjects with BHR at visit 1 were included and re-examined.

The presence of persistent asthma (PersA), clinical asthma remission (ClinR) and complete asthma remission (ComR) was determined at visits 2 and 3. ClinR was defined as the absence of symptoms (dyspnoea attacks and/or wheezing), without asthma medication over the last year, irrespective of the presence or absence of a positive BHR test (visit 2: PC10 (provocative concentration causing a 10\% fall in FEV1 (forced expiratory volume in $1 \mathrm{~s}$ ) histamine $\leqslant 16 \mathrm{mg} \cdot \mathrm{mL}^{-1}$; visit 3 : $\mathrm{PC}_{20}$ methacholine $\leqslant 39.3 \mathrm{mg} \cdot \mathrm{mL}^{-1}$ ) and/or normal FEV1 ( $>80 \%$ predicted pre-bronchodilator). ComR was defined as ClinR, combined with a negative BHR test and a normal $\mathrm{FEV}_{1}(>80 \%$ predicted pre-bronchodilator) (supplementary figure 1). Subjects with PersA still had symptoms and/or used asthma medication. Associations between childhood factors and asthma outcome (ComR versus PersA and ComR/ClinR versus PersA) at visits 2 and 3 were studied, by performing multivariate logistic regression with adjustments for sex and age at visit 1 using the SPSS 22 software (SPSS Inc, Chicago, IL, USA). A p-value $<0.05$ was considered statistically significant.

Of the initial cohort of 406 children, 209 had BHR at visit 1 . At visit 2, 188 subjects were re-assessed at a mean age of $25( \pm 2)$ years, of whom 25 only completed questionnaires. At visit 3,102 subjects with a mean age of $49( \pm 2)$ years were re-assessed, of whom 34 only completed questionnaires (supplementary figure 2).

Subjects who completed questionnaires only at visits 2 or 3 could only be classified as ClinR or PersA, as indications of BHR and FEV1 were missing. Subjects with questionnaire data at visit 2 only, had significantly lower FEV1/IVC (inspiratory vital capacity) values at baseline, compared to subjects with both questionnaire and spirometry data, without any other statistically significant demographic differences (supplementary table 1).

@ERSpublications

Asthma remission is rare but strictly defined complete asthma remission is persistent in most cases http://ow.ly/g0ZK30b1ACC

Cite this article as: Carpaij OA, Nieuwenhuis MAE, Koppelman GH, et al. Childhood factors associated with complete and clinical asthma remission at 25 and 49 years. Eur Respir J 2017; 49: 1601974 [https:// doi.org/10.1183/13993003.01974-2016]. 
TABLE 1 Childhood factors associated with complete and clinical asthma remission

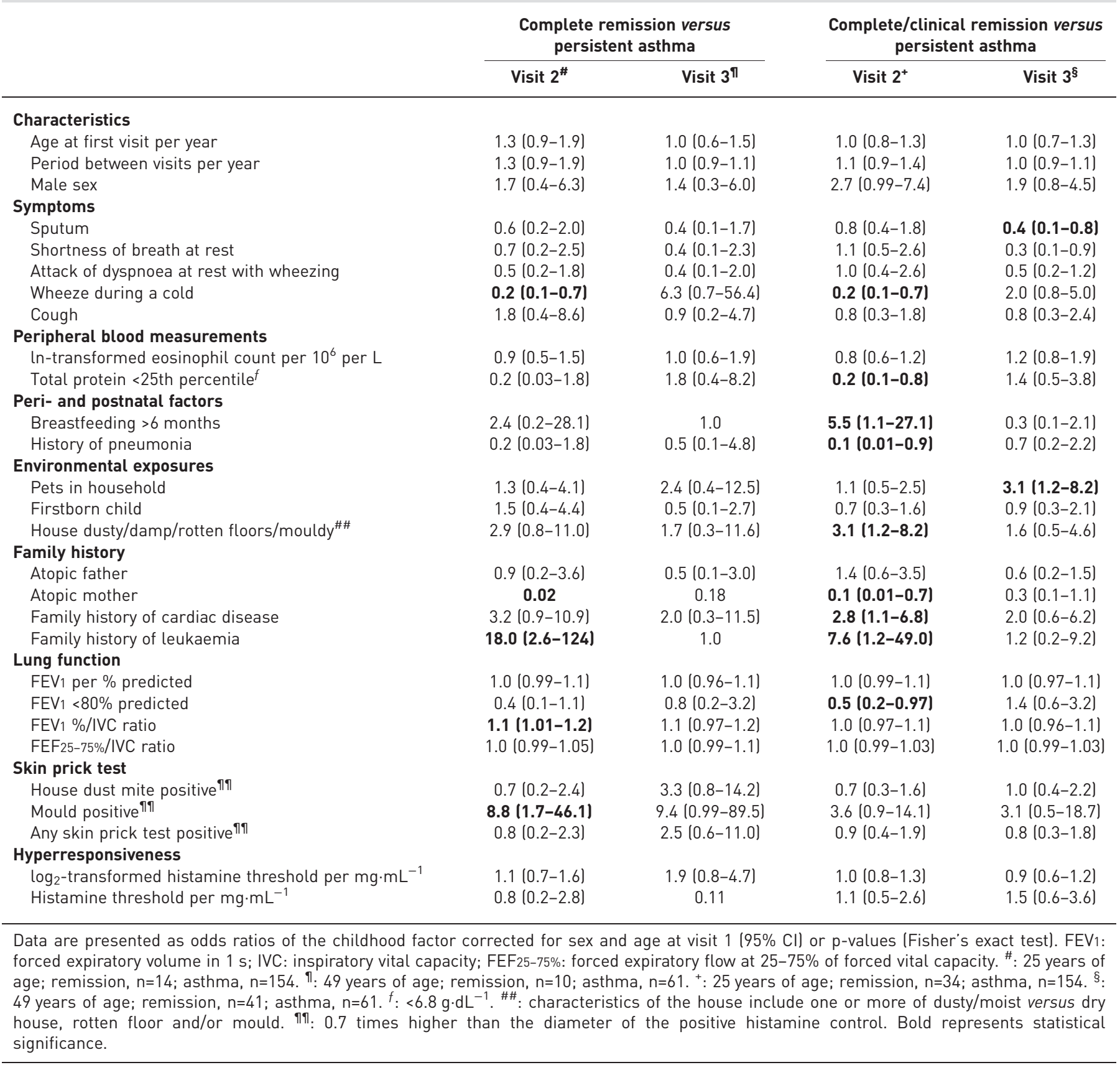

The prevalence of complete remission was $7 \%$ at age 25 and $10 \%$ at age 49 , indicating that ComR is a rare phenomenon. To our knowledge, only one other study using the same definition reported that $22 \%$ of children with asthma were in ComR after a follow-up of 30 years [6]. The prevalence of ComR in our study is probably an underestimation, because information on BHR and FEV1 was missing in almost half of the ClinR subjects.

Sixty-three subjects were fully examined during both follow-up visits (supplementary figure 3). Of all subjects with PersA at visit 2, 15 developed ClinR (29\%) and four developed ComR (8\%) at visit 3. Seven out of the 63 subjects (11\%) had ComR/ClinR between the ages 25 to 49 . The prevalence of asthma-relapse at visit 3 was $36 \%$, i.e. clinical asthma after ComR/ClinR at visit 2. Notably, using the strict definition of remission, $75 \%$ of the subjects with ComR at age 25 had no relapse of asthma by the age of 49 .

Table 1 shows results of the analyses of childhood factors associated with ComR versus PersA and ComR/ ClinR versus PersA. The variables presented are childhood factors associated with asthma remission in 
previous studies $[2,4,5,7-9]$ and statistically significant factors in the present study (supplementary tables 3-6 for complete results). Three childhood factors were positively associated with ComR at visit 2, i.e. a family history of leukaemia, a higher FEV //IVC ratio and a positive skin prick test to mould. Acute lymphocytic leukaemia has been previously associated with a lower prevalence of atopic diseases [10, 11]. This inverse relationship might be caused by an imbalance between Th1 and Th2 cells, predisposing the patient to either autoimmune or atopic disease [12]. Although only five children had a family history of leukaemia in our cohort, results suggest that this phenomenon might also play a role in asthma remission.

Two childhood factors that reduced the chance of ComR at visit 2 were symptoms of wheezing and an atopic mother. The finding of a lower frequency of ComR or ClinR at 25 years in the offspring of an atopic mother is consistent with the report of BURGESs et al., who found less frequent ClinR in similar subjects [3].

Four childhood factors increased the chances of ComR/ClinR at visit 2: being breastfed for more than 6 months; living in a dusty/damp house, with rotten floors and/or mould; and having a family member with cardiac disease, or with leukaemia. At visit 3, having pets during childhood was positively associated with ComR/ClinR. In addition, being breastfed for more than 6 months was associated with ComR/ClinR. A systematic review reported a reduced risk of asthma in breastfed children [13]. Furthermore, breastfed children are less susceptible to respiratory infections in early life, which are associated with the development and persistence of asthma [14]. Further studies are needed to assess whether prolonged breastfeeding also facilitates asthma remission when asthma has developed.

Five factors were found to reduce the chances of ComR/ClinR at visit 2, i.e. symptoms of wheezing during a cold; a total protein level <25th percentile; pneumonia during childhood; an atopic mother; and FEV1 $<80 \%$ predicted. At visit 3 , sputum production in childhood was negatively associated with ComR/ClinR (table 1). Children of an atopic mother had less frequent ComR/ClinR and ComR at 25 years, whereas no association with atopy in the father was observed. This finding is consistent with those of another study that found less frequent ComR/ClinR in children of a mother with asthma [3].

In conclusion, our study shows that over 39 years of follow-up, it is indeed possible to have persistent asthma remission after having childhood asthma, even though this was evident in only $11 \%$ of the subjects under investigation. Specifically, using the strict definition of complete asthma remission, we showed that when complete remission is present at age $25,75 \%$ of this group have persistent remission to age 49 . Several factors during childhood were found to be associated with a higher chance of asthma remission during adulthood, e.g. breastfeeding $>6$ months and a family history of leukaemia; and a lower chance of asthma remission, e.g. wheezing during a cold in childhood and an atopic mother. However, more research is needed to confirm our observations, using larger cohorts with a standard definition of asthma remission.

Orestes A. Carpaij ${ }^{1,2,5}$, Maartje A.E. Nieuwenhuis ${ }^{1,2,5}$, Gerard H. Koppelman $\circledast^{1,3}$, Maarten van den Berge ${ }^{1,2}$, Dirkje S. Postma ${ }^{1,2}$ and Judith M. Vonk ${ }^{1,4}$

${ }^{1}$ University of Groningen, University Medical Center Groningen, Groningen Research Institute for Asthma and COPD (GRIAC), Groningen, The Netherlands. ${ }^{2}$ University of Groningen, University Medical Center Groningen, Dept of Pulmonology, Groningen, The Netherlands. ${ }^{3}$ University of Groningen, University Medical Center Groningen, Dept of Pediatric Pulmonology and Pediatric Allergology, Beatrix Children's Hospital, Groningen, The Netherlands. ${ }^{4}$ University of Groningen, University Medical Center Groningen, Dept of Epidemiology, Groningen, The Netherlands. ${ }^{5}$ These authors contributed equally.

Correspondence: Judith M. Vonk, Dept of Epidemiology, University Medical Center Groningen, University of Groningen, Hanzeplein 1, 9713 GZ Groningen, The Netherlands. E-mail: j.m.vonk@umcg.nl

This article has supplementary material available from erj.ersjournals.com

Received: May 252016 | Accepted after revision: Feb 192017

Conflict of interest: Disclosures can be found alongside this article at erj.ersjournals.com

\section{References}

Upham JW, James AL. Remission of asthma: the next therapeutic frontier? Pharmacol Ther 2011; 130: 38-45.

2 De Marco R, Locatelli F, Cerveri I, et al. Incidence and remission of asthma: a retrospective study on the natural history of asthma in Italy. J Allergy Clin Immunol 2002; 110: 228-235.

3 Burgess JA, Matheson MC, Gurrin LC, et al. Factors influencing asthma remission: a longitudinal study from childhood to middle age. Thorax 2011; 66: 508-513.

4 Holm M, Omenaas E, Gíslason T, et al. Remission of asthma: a prospective longitudinal study from northern Europe (RHINE study). Eur Respir J 2007; 30: 62-65.

5 Rönmark E, Jönsson E, Platts-Mills T, et al. Incidence and remission of asthma in schoolchildren: report from the obstructive lung disease in northern Sweden studies. Pediatrics 2001; 107: E37. 
6 Vonk JM, Postma DS, Boezen HM, et al. Childhood factors associated with asthma remission after 30 year follow up. Thorax 2004; 59: 925-929.

7 Roorda RJ, Gerritsen J, van Aalderen WM, et al. Follow-up of asthma from childhood to adulthood: influence of potential childhood risk factors on the outcome of pulmonary function and bronchial responsiveness in adulthood. J Allergy Clin Immunol 1994; 93: 575-584.

8 Andersson M, Hedman L, Bjerg A, et al. Remission and persistence of asthma followed from 7 to 19 years of age. Pediatrics 2013; 132: e435-e442.

9 Limb SL, Brown KC, Wood RA, et al. Adult asthma severity in individuals with a history of childhood asthma. J Allergy Clin Immunol 2005; 115: 61-66.

10 Schüz J, Morgan G, Böhler E, et al. Atopic disease and childhood acute lymphoblastic leukemia. Int J Cancer 2003; 105: 255-260.

11 Wen W, Shu XO, Linet MS, et al. Allergic disorders and the risk of childhood acute lymphoblastic leukemia (United States). Cancer Causes Control 2000; 11: 303-307.

12 Liblau RS, Singer SM, McDevitt HO. Th1 and Th2 CD4+ T cells in the pathogenesis of organ-specific autoimmune diseases. Immunol Today 1995; 16: 34-38.

13 Lodge CJ, Tan DJ, Lau MX, et al. Breastfeeding and asthma and allergies: a systematic review and meta-analysis. Acta Paediatr 2015; 104: 38-53.

14 Rossi GA, Colin AA. Infantile respiratory syncytial virus and human rhinovirus infections: respective role in inception and persistence of wheezing. Eur Respir J 2015; 45: 774-789. 